
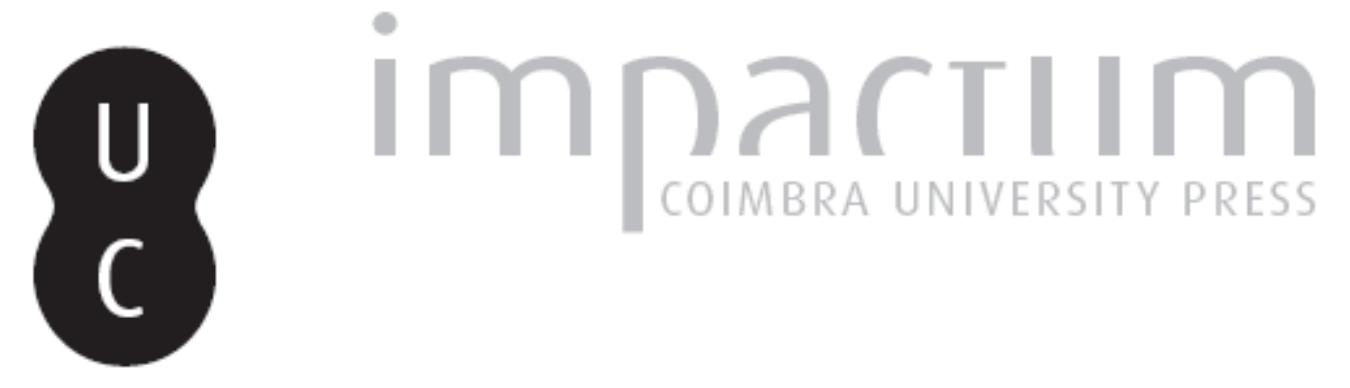

\title{
O periódico O Christianismo (1852) e a Revloução Francesa
}

\section{Autor(es): $\quad$ Pereira, José Esteves}

Publicado por: Imprensa da Universidade de Coimbra

URL persistente:

URI:http://hdl.handle.net/10316.2/43790

DOI:

DOI:https://doi.org/10.14195/2183-8925_10_31

Accessed : $\quad$ 26-Apr-2023 11:28:18

A navegação consulta e descarregamento dos títulos inseridos nas Bibliotecas Digitais UC Digitalis, UC Pombalina e UC Impactum, pressupõem a aceitação plena e sem reservas dos Termos e Condições de Uso destas Bibliotecas Digitais, disponíveis em https://digitalis.uc.pt/pt-pt/termos.

Conforme exposto nos referidos Termos e Condições de Uso, o descarregamento de títulos de acesso restrito requer uma licença válida de autorização devendo o utilizador aceder ao(s) documento(s) a partir de um endereço de IP da instituição detentora da supramencionada licença.

Ao utilizador é apenas permitido o descarregamento para uso pessoal, pelo que o emprego do(s) título(s) descarregado(s) para outro fim, designadamente comercial, carece de autorização do respetivo autor ou editor da obra.

Na medida em que todas as obras da UC Digitalis se encontram protegidas pelo Código do Direito de Autor e Direitos Conexos e demais legislação aplicável, toda a cópia, parcial ou total, deste documento, nos casos em que é legalmente admitida, deverá conter ou fazer-se acompanhar por este aviso.

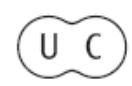


REVISTA DE HISTORIA DAS IDEIAS IO
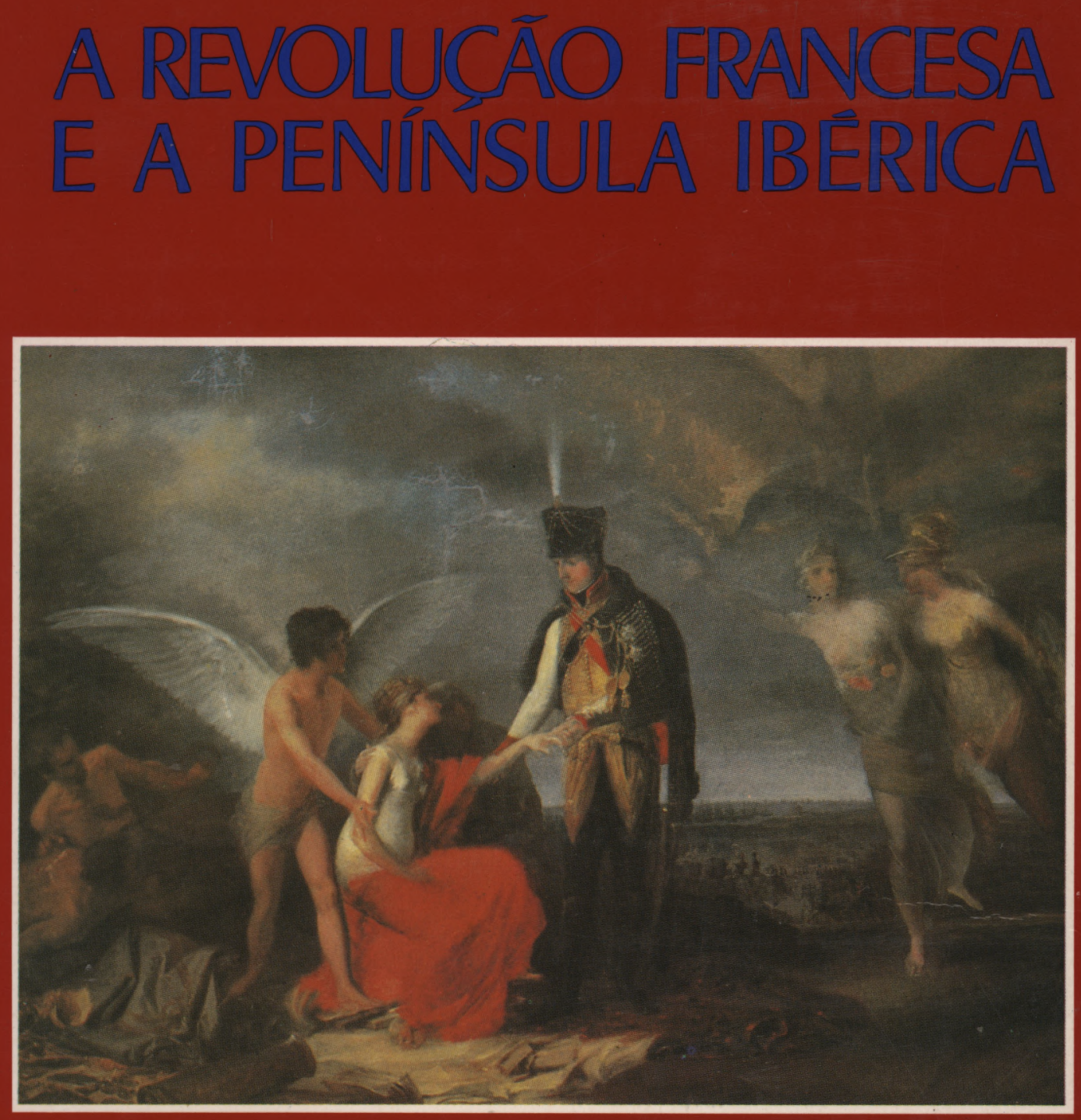

INSTITUTO DE HISTÖRIA E TEORIA DAS IDEIAS FACULDADE DE LETRAS 


\section{O PERIÓDICO O CHRISTIANISMO (1852) E A REVOLUÇÃO FRANCESA}

O semanário católico $O$ Christianismo, fundado em 1852 e apresentado, no seu primeiro número, de 3 de Janeiro, por Camilo Castelo Branco e Francisco Cândido de Mendonça e Melo é um indicador precioso sobre a revolução como ideologia. O labor do pequeno jornal corresponde ao interesse de pessoas e grupos empenhados numa renovação católica que é coeva do início do período da «Regeneração». Mas o que nos feriu mais a atenção foi o nexo conceptual de revolução, com especial relevância para $\checkmark$ que é aduzido sobre os acontecimentos de 1789 e anos seguintes.

A revolução, neste periódico, é, de facto, conceito operatório e ingrediente de comunicação para uma adequada sensibilização dos leitores a que se destina. Conhecido o jornal, pelo peso que teve na polémica de Camilo com Pedro de Amorim Viana, não foi menor a sua importância na invocação que faz do negativo da revolução procurando-se a redenção da sociedade, degenerada pela secularização crescente. Entremos na vida do periódico, escutando os apresentadores acima referidos:

«Subi aos visos de vossas montanhas. Vêde lá em baixo onde passam serenos os arroios por entre os frutos de vosso trabalho e da munificiência do Senhor! Ali naquele chão onde hasteais hoje uma cruz, vimos nós cravado o estandarte, da guerra civil... A guerra foi declarada aos estúpidos. O sangue correu em nome da filosofia. Os estúpidos eram os adoradores da cruz. Os filósofos eram os demolidores do templo» (1).

* Faculdade de Ciências Sociais e Humanas da Universidade Nova de Lisboa.

(1) O Christianismo, n. ${ }^{\circ} 1,3-1-1852, p$. 1. Trata-se de uma introdução ao jornal assinada por Camilo Castelo Branco e Francisco Cândido de 
Neste manifesto editorial, em que surge em pano de fundo a guerra civil pactuada em Gramido, não há ainda referências ao revolucionarismo, agente de impiedade mas, dobrada a folha, já no artigo Missões começamos a situarmo-nos melhor:

«Declinou esse astro maldito que, levantado do seio da França imoral, do alto dos Pirineus derramou na face do peninsula o seu fulgor sinistro!» (2).

Depois, ao longo das páginas dos sucessivos números do jcrnal, a focagem de espaços de sagrado que sofreram a profanação tornam-se mais impressivos. A utilização de St. Geneviève, por exemplo:

\begin{abstract}
"....quando entre o sagrado e o profano se ateava dura guerra, levando de vencida a execranda sombra do Mirabeau aos preciosos e venerandos restos da Santa Genoveva, a quem esses francos degenerados da antiga raça dos vencedores dos barbaros Unos, que essa santa, pia, corajosa e patriotica, havia feito parar ao mero som da sua voz no meio de sua devastadora marcha pelo coração da França agonizante concederam por maior homenagem a profanada praça de Grève, para onde foi arrojada" (3).
\end{abstract}

A par desta referência de espaço em que a revolução e as sequelas revolucionárias de todo um século emergem, assume importância $\supset$ papel que se atribui à revolução quando se abordam questões fundamentais para o jornal. A revolução aparece no avivar do prejuízo causado pelo corte entre Roma e o Mundo. Por isso se sublinha a importância das missões em tudo o que podem importar de reconstrutivo do desmoronamento da centralidade romana.

A um tempo e a um espaço profanados que vão a par da dispersão dos laços que a legitimidade e a transcendência da

Mendonça e Melo. Sobre Camilo, nesta fase da sua criação, cf. A. Prado Coelho, Espiritualidade e arte de Camilo, Porto, Liv. Simões Lopes, 1950, pp. 14-16. Mendonça e Melo, um dos fundadores do jornal legitimista "O Ecco», traduz em 1845 o Du Pape de José de Maistre (Cf. Inocêncio, Dic. Bibliog., II, p. 362). Camilo abandona O Christianismo em meados de Setembro de 1852. A partir do n. ${ }^{\circ} 38$, de 18-9-1852 já não é colaborador. Mendonça e Melo permanece como director. Entretanto, no n. 39 de 25 de Setembro anunciava-se novo jornal, $A$ Cruz, redigido por Camilo.

(2) O Christianismo, Idem, p. 3, art. de C. C. Branco.

(3) Idem, artigo do P. José Mendes de Paiva. Sobre as vicissitudes setecentistas e oitocentistas do panteão de St. Geneviève cf. 0 . Chadwick, The secularisation of the european mind in the eighteenth century, Cambridge, Cambridge University Press, 1979. 


\section{O Periódico O Christianismo}

fundamentação do poder vinculam, sucedem as consequências nefastas do regalismo e do jansenismo, consorciadas com a invasão da dúvida e do filosofismo:

«Bayle semeara a dúvida nas discussões religiosas. Voltaire salgara-as com o ridículo. Rousseau invectivara a desigualdade das condições. Helvetius dissera que a alma era uma quimera. Hobbes dera a natureza como único Deus possível. 0 sangue da revolução francesa caiu na posteridade que aplaudira a obra daqueles responsáveis por tantas agonias»(4).

A invocação das vicissitudes da revolução, do próprio absolutismo reformista, não são mero exercício de expiação a que Camilo quer convidar os leitores:

«E doloroso comemorar estes factos, que a muito custo, desassombramos das cores negras com que devem ser descritos. Mas é um serviço à humanidade lembrar-lhe frequentes vezes o que é a impiedade e que funestas consequências derivam dela» $\left({ }^{5}\right)$.

Apesar do apelo de redenção, da apologética implícita, e implícitas leituras de Bergier, de de Maistre, de Chateaubriand, e ovitros, há um aproveitamento militante que visa intervir no tcdo da sociedade. Como confirma Latreille «aos olhos dos católicos, $a$ revolução deixa quase de ser um acontecimento histórico com suas singularidades, os seus acidentes, os seus casos fortuitos» $\left({ }^{6}\right)$, para tomar o aspecto duma doutrina social e política. E, justamente, esse sentido o que se colhe quando vemos a pretensão de alguns dos colaboradores do $O$ Christianismo buscando o revigoramento do pensamento católico (distante ainda do aggiornamento tomista para uma arquitectura filosófica, do teológico ao político) (7) e apontando as trevas do filosofismo "galvanizado pela revolução». E apontando, também, a fraqueza da regeneração meramente social, meramente político-económica, meramente filantrópica:

"Quiseram.... substituir ao sentimento divino um moderno sentimento humano, riscando dos corações a palavra "caridade» para escrever um código de regimen social uma ovtra palavra, que a impostura descrita apelida filantropia.

(4) O Christianismo, 21-8-1852, n. 34 , art. de C. C. Branco com o título "Retrospecto Doloroso".

(5) Idem, ibidem.

(8) Cf. A. Latreille, L'église catholique et la révolution française, Paris, I.es éditions du Cerf, 1970, T. II, p. 287.

(7) E algo distante, também. do Syllabus, de Pio IX. 


\title{
Revista de História das Ideias
}

\begin{abstract}
A filosofia política sentada no seu trono de quimeras e cortejada pela coorte dos que se prometiam uma existência dourada no galvanismo das revoluções, levantou a mão imperiosa para o céu e mandou suspender a influência que de lá descia sobre a existência das sociedades. Lutando contra Deus, o génio das reformas, o racionalismo, filho primogénito do orgulho humano e pai de quantas extravagâncias rebaixam a lei da sua influência salutar. prometia-se uma vitória infalível» ${ }^{(8)}$.
\end{abstract}

É a esta luz que, transcendência e experiência, cristianismo 'a filosofismo, razão e fé se traduzem num discurso acessível e em versos edificantes, tendo-se presente a memória de um público que tem associada revolução e impiedade:

«Disse, falando de Voltaire, referindo-me ao testemunho dum dos seus discípulos que ele preparara as revoluçōes políticas e religiosas que inundaram a Europa de sangue, de crimes e desordens. Na biografia universal de Feller citam-se para prova desta verdade, muitos escritores que assim o tem reconhecido, e entre estes o Mercurio de França de 7 de Agosto de 1790, em que seus autores mostram que a revolução francesa de 1789 foi obra de Voltaire, e que, se ele não viu tudo, o que se fez, foi ele que fez tudo, o que se viu. Disse que imprimiu no seu século o seu espírito de corrupção e imoralidade» $\left({ }^{(}\right)$.

Esta leitura de revolução viria, porém, a moldar-se de forma mais impressiva em texto de Camilo Castelo Branco, intitulado Retrospecto Doloroso, mais tarde coligido nas suas Horas de Paz, com o significativo título de Festa da Razão. Seja indicador esta pequena citação:

«Doi-se o coração, e recusa o entendimento historiar a inauguração desse gigante imoral, que veio cevar-se em cadáveres, e sentar-se em tronos, e vitoriar-se em ruínas, que são ainda hoje os cimentos sobre que o século XIX intenta edificar o seu monumento de regeneração social. Queremos falar dessa época chamada terror, epiteto expressivo, que substitui o de IMPIEDADE" (10).

Dois aspectos mais, na leitura que possamos fazer deste jornal, sobre conotações de revolução nos importam. Primeiro aspecto, a) o que se prende com a relação de Revolução e Antigo

(8) O Christianismo, 15-5-852, n. ${ }^{\circ} 20$, art. de C. C. Branco, com o título "Caridade», p. 117. Neste artigo, Camilo serve-se de referências da Encyclopédie Catholique no que respeita a problemas sociais.

( $\left.{ }^{9}\right)$ Idem, 6-11-1852, n. ${ }^{\circ} 45$, art. da autoria de Alvaro Vaz Correia de Seabra e Silva, com o título "Apêndice ao artigo sobre o Deismo».

(10) Idem, 21-8-1852, n. 34 , p. 214. 


\section{O Periódico O Christianismo}

Regime (na sua fase de absolutismo esclarecido) sendo a segunda anotação crítica que pretendemos fazer para melhor compreensão das linhas orientadoras do jornal b) a temática atinente ao jansenismo e a Kant.

Quanto à articulação de Revolução e Antigo Regime, refere-se-lhe o articulista Mendonça e Melo em lance que engloba a expulsão dos jesuítas e a secularização do ensino:

"Quando o ensino se achava em brilhante pé, começaram os jansenistas e outros bem conhecidos sectários a insinuar-se com os governos civis, e a envenenarem as intenções dos professores religiosos, com especialidade os Jesuitas, e não foram mal sucedidos em seus ardilosos e infames manejos. Conseguiram banir a Companhia de Jesus; e por esse meio fazer passar as aulas superiores para mestres seculares, que mudaram inteiramente o método de ensino. Os frutos desta mudança, e da de todo o ensino, bem se tem conhecido nas quasi constantes revoluções e desordens que tem invadido todos os estados civilizados, e que quasi se tornaram normais nestes ultimos tempos» (11).

A referência ao método no que possa querer dizer de perversão da essencialidade de um conhecimento e organização de saberes hierarquizados, transcendentemente, reencontra-se na omnipresente desvalorização racionalista. E com esta referência poderemos então aludir a um segundo aspecto que envolve, quer a matriz jansenista, de pensamento e espiritualidade, quer a leitura que se pretende fazer de Kant e do racionalismo idealista decorrente.

O perigo da dúvida, da insegurança, do erro dos caminhos, vem do jansenismo e da filosofia de Kant. Alvaro Vaz Correia de Seabra e Silva reforça a sua «tese» sobre o deísmo, suplementando-a com uma Breve notícia da filosofia de Kant. E não surgindo na «notícia» menção expressa à revolução, é evidente a articulação desta com a crítica kantiana pelo que terá de «abjecta e degradante para o espírito humano como é toda a ciência que prescinde das luzes da fé (subl. nosso), e da religião, e que tem por único esteio e fundamento o orgulho do homem e as fracas luzes do seu espirito» (subl. nosso). Força-se o argumento salientando o que de desafiador de uma «auctoritas» contém as influências racionalistas, no terreno teológico, do jansenismo:

(11) Idem, 23-10-1852, n. 43, p. 268, art. de Mendonça e Melo intitulado "Das Escolas Superiores». 


\section{Revista de História das Ideias}

«E pois a nova filosofia de Kant um novo sistema, que a impiedade descobriu para combater o cristianismo; é uma nova campanha sob a direç̧ão de outros chefes; não se combate abertamente a religião como no sistema de Voltaire, isto é, por uma guerra viva, e por manifestas hostilidades contra ela; pretende-se conseguir o mesmo fim por um modo mais pacífico, mas talvez mais pernicioso, porque mais astuto, e manhoso; explica-se o cristianismo pela razão para o destruir; faz-se dele um sistema de filosofia moral como o de Zoroastres ou Confúcio ou de qualquer outro filósofo, isto é, considera-se como uma obra puramente humana e como tal se explica. Esta guerra ou esta nova espécie de combate tem muita semelhança com aquele, que os jansenistas fizeram à Igreja intentando destrui-la pela mesma Igreja, pondo em execucão talvez o sistema mais bem combinado, que o inferno podia sugerir contra ela. Se os jansenistas, pois, trataram de destruir a igreja pela igreja, os kantistas pretendem destruir o cristianismo pela sua razão crítica, ou pelas suas explicações filosóficas» (12).

A inversão dos fundamentos manifestados pelos dois aspectos que acabamos de referir são dois fortes indicadores para encontrarmos o que verdadeiramente está no centro deste jornal: A reacção. Curiosamente, o último artigo do ano de 1852, terá por título $D a$ reacção religiosa.

Estamos, nestas colunas, perante a imagem do mundo marcado pela revolução redimível enquanto vingarem o apelo à transcendência de fundamentos e correlata transcendência de poder, com a necessária mediação de condições políticas. Só assim Portugal poderá emendar os «erros a que a revolução o conduziu». Revolução que é filha do ciclo europeu de revolucionarismo iniciado em 1789, prolongado em 1830 e 1848:

«Em 1830 - diz o militante legitimista Mendonça e Melo - quando um Orleans regicida ousou pôr mão sacrílega sobre a coroa do herdeiro de S. Luis, desencadeou-se a irreligião em todos os países, que seguiram a sorte revolucionária da França» (13).

Segue-se, então, a advertência aos governantes portugueses no fecho do artigo; em linguagem extremista, detractora de tudo o que possa pressupor um universo de secularização:

(12) Idem, 4-12-1852, n. 49 , pp. 310-311. Art. de Alvaro Vaz Correia de Seabra e Silva. "Suplemento ao artigo sobre o deísmo ou breve notícia da filosofia de Kant». e Melo.

(13) Idiem, 25-12-1852. Art. «Da reacção religiosa», de Mendonça 


\section{O Periódico O Christianismo}

«O povo português conhece que é longo o caminho que tem a percorrer para se arredar do mal; precisa de bons guias, e é por isso que não cessa de clamar que lhe restituam as ordens religiosas. Eis, pois, senhores do governo, dai-nos frades por que os precisamos para que nos ajudem a levar o fardo pesado desta vida, e adquirir as venturas inapreciáveis da outra» $\left({ }^{14}\right)$.

Antes de terminar esta pequena incursão de leitura em jornal católico de 1852 julgamos necessário pontuar um aspecto que se prende com um desvalorizar de tempo revolucionário e sentido revolucionário, mesmo quando é visto, por Camilo, no horizonte da expiação dos erros do mundo. Toda e qualquer regeneraçāo (estamos em 1852), só é possível pela regeneração do cristão e restituição de bens eclesiásticos. Outro mundo é aquele que pesa na quotidianiedade liberal, pelo menos ao nível de fundamentos jus-políticos mas que não é razoável-como sessenta anos antes, o não fora:

«...foi celebrada a primeira festa da razão, na Igreja de Nossa Senhora. A esposa de um tipógrafo representava de Deusa. Vestiram-na de branco, engrinaldaram-na de rosas, soltaram-lhe os cabelos pelas espáduas e levantaram-na em um trono, levada por quatro beneméritos cidadãos.... Fouquier-Tinville fizera erguer o patíbulo na sala imediata à das condenações: Isto vai óptimo, dizia ela-As cabeças caem como as ardósias, mas na década próxima há-de ser melhor ainda.... Robespierre era deísta e fez decretar à Assembleia que o povo francês acreditava na existência de Deus e imortalidade da alma. Em quanto a si declarou-se Sumo pontífice do Culto" (15).

O sarcasmo está longe de ser gratuito e destina-se a uma faixa social extensa e enraizada em Fé. A caricatura dos factos, deste texto camiliano já citado, Retrospecto Doloroso, é umạ desvalorização e um retirar de sentido a um tempo revolucionário, reportando, afinal, toda a sua fenomenologia a matrizes de transitório e inumano.

A redenção da revolução far-se-á não por acção contrária (é absolutamente necessário, aqui, lembrar entre outras influências de pensamento J. de Maistre) mas um horizonte sotereológico.

"Saudamos o futuro!

Ao longe, onde se fecham os horizontes escuros deste século que passa, vemos o anjo das crenças descer, irra-

(14) Idem, ibidem.

(15) Idem, 21-8-1852. Art. "Retrospecto Doloroso», de C. C. Branco iá citado nesta comunicação. 
diante de luz, sobre o berço das gerações porvir! Salve! homem do futuro, que levantas a fronte para o teu Deus, e não tens a dúvida da desanimadora incerteza a entorvar-te a luz do entendimento» (16).

Desejava-se, como que ausente, a «ilusão da razão» que é a revolução, revolução que em Kant, vituperado no jornal, se entende, antes, como «facto de razão», facto que insere sentido profundo de realização da humanidade $\left({ }^{17}\right)$.

(16) Idem. 3-1-1852, Introd., p. 1.

(17) Cf. Kant, Conflito das Faculdades, VI; G. Gusdorf, Les Sciences Humaines et la pensée occidentale, (vol. III), Paris, Payot, 1978, p. 45. La conscience revolutionnaire - Les Idéologues. 